\title{
The Linguistic and Social Aspects of the Bedouin Dialect
}

\author{
Mahmoud El Salman \\ King Faisal University, Saudi Arabia \\ E-mail: el_salman@hotmail.com
}

Doi:10.7575/aiac.alls.v.7n.4p.20

Received: 08/02/2016

URL: http://dx.doi.org/10.7575/aiac.alls.v.7n.4p.20

Accepted: 22/04/2016

\begin{abstract}
This is a sociolinguistic study that tries to investigate the peculiarity of the Bedouin dialect regardless of the place where it is used. Some variants that are used in their dialect are used wherever they are from. Two sounds in particular were chosen to carry out this study. These are the /ds/ variant of the (Q) variable, and the /ts/ variant of the (K) variable. The study shows that some sounds that are known to be exclusively used by Bedouins, are still used by the old Bedouins wherever they live. For example, Old informants from Jordan used the /ts/ variant within the tribe domains, and the old informants from other tribes living in Saudi Arabia used it as well. This is also seen with regard to the /dy/ sound. The /ds/is used also in relatively high percentage in the speech of the old in Jordan and Saudi Arabia. This shows that belonging to the Bedouin group per se, is what matters in determining the sound used regardless of the region to which one belongs. Unlike the rural people who might use the different alternates of the $(\mathrm{Q})$ variable depending on the region to which they belong, for example, $[\mathrm{k}]$ is used in some parts of Palestine while [q] is used in other parts like Tirat Haifa village in the northern part of Palestine. Bedouins are consistent in using the $[\mathrm{g}]$ variant or the /dz/ of the (Q) variable regardless of the area where they live. In other words, the two sounds appear in the dialects of the Bedouins whether they live in Jordan or Saudi Arabia. This raises the possibility that their sharing the same culture (being Bedouins) leads to their sharing these linguistic features. Part of their culture is belonging to their tribes as they are traditionally divided into tribes. The dialect of the tribe remains important where ever they are.
\end{abstract}

Keywords. Linguistic variation, variant

\section{Introduction}

This study investigates the use of some sounds that are peculiar to Bedouin dialects. Because the variant [ts] of the (K) variable, and the voiced affricate/ds/ variant of the $(\mathrm{Q})$ variable are the key features of the dialect of this group, they will be used as a basis in investigating this variation.

The $/ \mathrm{K} /$ variable has three variants. These are: the velar $/ \mathrm{k} /$, the affricate voiceless stop $/ \mathrm{t} / \mathrm{and}$ the dental $/ \mathrm{ts} /$. So, a word like "kiif", could be pronunced as: /kiif/, /t f fiif/, and tsiif/

The $(\mathrm{Q})$ variable is also an important sound in the Arabic dialects. Abdel-Jawad states that "because of the social and geographical importance of this variable $[(\mathrm{Q})]$ as a carrier of local or regional loyalties, it has often been used by dialectologists as the main criterion for establishing the dialect boundaries or isolosses in the Arabic dialects" (AbdelJawad, 1981: 159). The variable (Q) has four major variants: the voiceless uvular stop [q], the voiced velar stop [g], the voiceless velar stop [k] and the glottal stop [?]. The (Q) also has other important variants. These are $/ \mathrm{dz} /$ and $/ \mathrm{dz} /$. For example, in Hail (Saudi Arabia), a word like qarryah "village' might be pronounced like /dzaryyah/. In Bedouin dialects, a word like abriiq "pot" could be pronounced as /abriidz/, where the variant/q/ is realized as /dz/.

Although they are scattered through different parts of the Arab world, the Bedouins still preserve some of the linguistic aspects of their dialects that are considered to be peculiar to them, and shared among them regardless of the area where they live. For example, the Bedouins who live in Jordan, still preserve some sounds that are also found in the Bedouin dialect that is used in other area, for example in Saudi Arabia. Despite the long distance that exists between the two groups, the dialect they use is almost similar in that the phonetic inventory of them still has some sounds that disappear completely from the dialects of the other groups who live so close to them. This what makes it possible, from our viewpoint, to talk not only about language community (Mestrie, 2000), but also we can talk about dialect community, where almost the same dialect is used in different countries. Thus, the study aims to investigate the use of the two variants, /ts/ of the (K) variable and [d $]$ of the $(\mathrm{Q})$ variable, in the speech of two Bedouin groups from Jordan and Saudi Arabia.

\section{Methodology}

The aim of this study is to investigate the dialects of some Bedouins who live in different parts of the Arab world, specifically, Jordan and Saudi Arabia.

This study has been conducted in light of the Labovian Paradigm. The interviews were carried out in shops, universities and houses in order to get a random and diverse groups for the study. This was determined by the possible availability of the informants. The social network framework was followed and the informants were approached in the capacity of "a friend of a friend" or in some cases "a friend of a friend of a friend" (Milroy and Milroy, 1978). 
To test the hypothesis that wherever the Bedouins live, they adopt the same dialect, two groups of them were chosen. One in Saudi Arabia and the other in Jordan In addition to that, other important studies that investigate the Bedouin or the rural dialects were considered, namely (Abid al Jawad, 1981, Al Khatib, 1988, Kanakri, 1988, Al Wer, 1991, El Salman, 2003, El Salman and Al Haisoni, 2013). The two variants that were used for the investigation of this possibility were the /ts/ sound as well as the /dz/ sound. The study is empirical in its method in that it is fully dependent on naturalistic speech. All the interviews, that were conducted in Saudi Arabia and Jordan, used the face-to-face technique for obtaining data with regard to linguistic variation.

In order to carry out this investigation, 48 old Bedouin informants were interviewed. 24 from Jordan and 24 of them were from Saudi Arabia. In addition to that, 48 old informants from the rural groups were interviewed. 24 from Saudi Arabia, and 24 from different villages in Palestine and Jordan.

The size of the sample used in this study is acceptable because it is similar to the number of informants used or interviewed in many similar studies, such as the number of informants in Trudgill's (1974) study, this was 60 in a city with a population of 118,610 . The number of informants that were interviewed in Daher's study (1998) conducted in Damascus, was 46. Labov also noted that "the structure of social and stylistic variation of language can be studied through samples considerably smaller than those required for the study of other forms of social behaviour" (Labov, 1966: 638).

Old informants were chosen because the old are found to preserve their native dialect more than the members of the middle aged group or the young and therefore tend to be more reliable. It is a very well documented fact that the elderly are subject to much more pressure from their society to preserve their native dialect than the young (Walter, 1991: 201). Eckert also reports that "community studies of variation frequently show that increasing age correlates with increasing conservatism in speech" (Eckert, 1997: 157).

\section{The variables}

The first sound to be used in the study is the /ts/ variant.

The dialect of the Bedouin group is one of the very few Arabic dialects that still actively uses the variant [ts] in its phonetic inventory. My paper documents a linguistic phenomenon which is very important to the sociolinguistic debate in Arabic linguistics. This concerns the variable $/ \mathrm{k} /$ and its variant [ts] which is rarely used in the Arab world.

The use of such sounds outside the perimeters of the tribe might be avoided simply because it is considered to be a sound that is stigmatized or possibly unknown outside the tribe within which it is used. In short, the variant is not widely understood. As a result, its use renders common words totally indecipherable to Arabic native speakers. The words were not simply recognized when pronounced with the /ts/ sound. Examples of these words collected from the face to face interviews are: /shantitits/ (/shantitik/) 'your bag;' /kiif halits/ (/kiif halik/) 'how are you;' and many others.

The velar is realised as [ts] most often near front vowels. The data also show that the /k/ can be realised as //ts/, wordinitially, word-finally and word-medially. The following are examples when it is used word-finally: (the data are taken from El Salman, 2016).

$\begin{array}{ll}\text { /ya zinik/ } & \rightarrow \text { /ya zinits/ "how beautiful you are" } \\ \text { / kiif halik/ } & \rightarrow \text { /tsiif halits / "how are you' } \\ \text { /kitabtik/ } & \rightarrow \text { /kitabits/ "your book" } \\ \text { /hadak/ } & \rightarrow \text { /hadats/ "your limit" } \\ \text { /bitnik/ } \rightarrow & \text { /bintits/ "your daughter }\end{array}$

Data taken from Jordan also show the use of the /ts/ variant in similar context:

/bitik/ ---------------/bitits/ "your house"
/ratbik/ -------------/ratbits/ "your salary"

The following examples that were taken from our interviews indicate that the [k] can also be realised as [ts] wordmedially:

$$
\begin{aligned}
& \text { /yifakir/ } \rightarrow \text { /yifatsir/ "he thinks" } \\
& \text { /bakito/ } \rightarrow \text { /batsito/ "you made him cry" } \\
& \text { /yakwi/ } \rightarrow \text { /yatswi "iron" }
\end{aligned}
$$

Data taken from informants in Jordan show the same possibility of using the /ts/ word-medially: 
The following examples that were also taken from our interviews when the [k] was realised as [ts] word-initially:

kiif/ $\rightarrow$ /tsiif/ $\quad$ "how”
$/$ kalb/ $\rightarrow$ tsalb/ $\quad$ "dog"
$/$ kaf/ $\rightarrow$ tsaf/ $\quad$ "palm"
$/$ kabiir/ $\rightarrow$ /tsabiir/ $\quad$ "big"

Data from Jordan also show the use of /ts/ word-initially:

/kiif/-------------------/tsiif/ "how"

Kibd-----------------------/tsibd// "kidney"

\subsection{The $(/ \mathrm{d} / \mathrm{s})$}

The affricate $/ \mathrm{d} z /$ is one of the variants of the $(\mathrm{Q})$ variable.

The Standard Arabic voiceless uvular stop (Q) is in many areas the most salient phonological feature by which speakers of colloquial Arabic varieties can be identified. It has at least five reflexes; [q], [g], [k], [d3] and [?] in present-day spoken Arabic. Arab linguists (e.g. Abdo 1969; Abdel-Jawad 1981, Kanakri, 1988, Al Khatib, 1988, Al Wer, 1991) have frequently used (Q) with its various allophones as a parameter for drawing lines between the different dialects in Arabic.

Blanc (1964) states that (Q) has undergone several changes. Some of these are related to the group of dialects described by Blanc as geltu-dialects (the dialects characteristic of Bedouin people) and others to the group of dialects described as qeltu-dialects (the dialects related to urban and rural regions, which constitute the sedentary Arab population). In Bedouin or semi-Bedouin dialects (the dialects of people who do not live a fully Bedouin life, among whom are the people of Hai'l, of Southern Iraq and the Jordanian and Syrian deserts, (Q) is realised as [g] (Abdel Jawad,1981; Kanakri, 1988; Irshied, 1984). In other Bedouin dialects further changes took place leading to the realisation of the front allophones of /g/ as [3] or [d3] (Abdel-Jawad 1981; Kanakri 1988; Al Khatib 1988).

\section{Findings and discussions}

Table (1) shows that the [d] variant is used in 30\% in the speech of the old male informants in Saudi Arabia, and $20 \%$ among old females of the total number of occurrences of the $(\mathrm{Q})$ variable.

Table 1. The distribution of the variable (Q) by sex in the speech of Saudi Bedouins.

\begin{tabular}{|c|c|c|c|c|c|c|c|c|}
\hline Sex & $\mathrm{M}$ & & & & $\mathrm{F}$ & & & \\
\hline & {$[q] \%$} & {$[\mathrm{~g}] \%$} & {$[\mathrm{k}] \%$} & {$[\mathrm{~d}]$} & {$[\mathrm{q}] \%$} & {$[\mathrm{~g}] \%$} & {$[\mathrm{k}] \%$} & {$[\mathrm{~d}]$} \\
\hline Old & 2 & 68 & 0 & 30 & o & 80 & 0 & 20 \\
\hline
\end{tabular}

Table (2) shows that the variant is used in the speech of Old Bedouin in Jordan. The rates are $25 \%$ among old males and 18 among old females.

Table 2. The distribution of the variable (Q) by sex in the speech of Jordanian Bedouins.

\begin{tabular}{lllllllll}
\hline Sex & M & \multicolumn{7}{c}{$\mathrm{F}$} \\
\hline & {$[\mathrm{q}] \%$} & {$[\mathrm{~g}] \%$} & {$[\mathrm{k}] \%$} & {$[\mathrm{~d}]$} & {$[\mathrm{q}] \%$} & {$[\mathrm{~g}] \%$} & {$[\mathrm{k}] \%$} & {$[\mathrm{~d}]$} \\
\hline Old & 5 & 75 & 0 & 25 & 2 & 80 & 0 & 18 \\
\hline
\end{tabular}

Table (3) shows that the variant is not used at all by the old of the rural groups taken from Saudi Arabia, Tiart Haifa (Jordanians who are originally from Tirat Haifa in Palestine), Dora (Palestine), Malka (Jordan) and Silat al Dahir ( Jordanians who are originally from silat Al Dahir in Palestine.

Table 3. The distribution of the variable (Q) by sex in rural areas.

\begin{tabular}{lllllllll}
\hline Sex & M & \multicolumn{7}{c}{$\mathrm{F}$} \\
\hline & {$[\mathrm{q}] \%$} & {$[\mathrm{~g}] \%$} & {$[\mathrm{k}] \%$} & {$[\mathrm{~d}]$} & {$[\mathrm{q}] \%$} & {$[\mathrm{~g}] \%$} & {$[\mathrm{k}] \%$} & {$[\mathrm{~d}]$} \\
\hline Old & 33 & 51 & 16 & 0 & 25 & 53 & 22 & 0 \\
\hline
\end{tabular}


The table above shows that three variants of the $(\mathrm{Q})$ variable appear in the speech of the four rural groups. These were /k/ in Sialt Al Dahir, /q/ in Tirat Haifa, /g/ in Malka, and /g/ in Dora. Which means that we cannot conclude that any of these variant is a key feature of rural dialect in general, because, while one of these variants is used in one of the chosen rural areas, the other is not used. All of the variants appear in their speech and all of the informants interviewed belong to the rural group. For, example, the /q/ is the key feature of the Tirawi dialect, the $/ \mathrm{k} /$ is the key feature of the Silawi dialect, the $/ \mathrm{g} /$ is the key feature of the Malkawi and the Dori dialects. The place and the name of the village determine the variant used, while in the case of the Bedouin informants, belonging to the Bedouin group can help to predict the variant used.

The same has been seen with regard to the /ts/ variant of the $(\mathrm{K})$ variable. Table (4) shows that the /ts/ appears in the speech of old Bedouin informants from Saudi Arabia in high percentage,

Table 4. The distribution of the variable (k) by sex in the speech of Saudi Bedouins

\begin{tabular}{llllll}
\hline Sex & \multicolumn{4}{l}{ F } \\
\hline & {$[\mathrm{k}] \%$} & {$[\mathrm{ts}]$} & {$[\mathrm{k}] \%$} & {$[\mathrm{ts}]$} \\
\hline Old & 50 & 40 & 55 & 45 \\
\hline
\end{tabular}

Table 5. The distribution of the variable $(\mathrm{k})$ by sex in the speech of Jordanian Bedouins

\begin{tabular}{llllll}
\hline Sex & \multicolumn{4}{l}{ M } & F \\
\hline Age & {$[\mathrm{k}] \%$} & {$[\mathrm{ts}]$} & {$[\mathrm{k}] \%$} & {$[\mathrm{ts}]$} \\
\hline Old & 70 & 30 & 58 & 42 \\
\hline
\end{tabular}

while table (6) shows that the /ts/ ceases to appear in the speech of the informants of the rural group regardless of the place they are from. The percentage of the /ts/ is 0 in both the male and the female

Table 6. The distribution of the variable $(\mathrm{k})$ by sex in rural areas.

\begin{tabular}{llllll}
\hline Sex & M & \multicolumn{3}{l}{} & \\
\hline Age & {$[\mathrm{k}] \%$} & {$[\mathrm{ts}]$} & {$[\mathrm{k}] \%$} & {$[\mathrm{ts}]$} \\
\hline Old & 100 & 0 & 100 & 0 \\
\hline
\end{tabular}

Therefore, what could be deducted or concluded from the tables is that the two sounds appear in the dialects of the Bedouins whether they live in Jordan or Saudi Arabia. This raises the possibility that their sharing the same culture (being Bedouins) leads to their sharing these linguistic features. Part of their culture is belonging to their tribes as they are traditionally divided into tribes. The dialect of the tribe remains important where ever they are.

Social habits thus are able to create similar linguistic habits. Socially speaking, Bedouin tribes have some social aspects that are almost similar where ever they live. The correlation between you being Bedouin and the dialect you use regardless of the place you live is very strong, resulting in a very a unique situation for Bedouins. Notice that your being classified as rural or urban does not help to predict the dialect used by you without knowing the region to which you belong. In other words, it is the region that helps to predict the dialect you use but not your being rural or urban. This similarity between the dialects of the Bedouins regardless of the place confirms the possibility of them having or coming from the same origin.

The name of the tribe or the clan is also important for rural groups. But rural groups in the past used to stay in one place for a long period of time. So, it is not uncommon to find some people who belong to rural groups have the name of the place where they live as a surname as a result of staying in the place for a long period of time. The dialect of the place, as a result, became important, and an important sign of belonging to the place. Many different families might live in the same rural area and at the same time they all use the dialect of the place. You might also find the same rural clan live in different places, and each group use the dialect of the place where they live. For example, some rural groups who belong to the same root might be found to live in a village in Jordan and the other group live in another village in Palestine. It is also normal to find each group, though belonging to the same root and the same surname, use different variants of the same variables. In other words, different dialects, for example, Al AbtaH family members who live in Tirat Haifa (Palestine), use the uvular /q/ variant of the (Q) variable. While Al AbtaH family members who live in the villages in the northern part of Jordan, use the /g/ variant of the (Q) variable. Notice that the velar [g] and the uvular [q] are two variants (allophones) of the $(\mathrm{Q})$ variable.

In addition, many rural groups are named after the name of the place where they live. Rural groups who live in Tirat Hafa, for example, are known as Tirawis, though they belong to different families, and those who live in Malka (Jordan) are called Malkawis. Bedouins belong to tribes and are normally taken the name of their tribes as their surnames. In 
other words, their belonging and adhering to their tribes made them adhere to the dialects of the original tribes to which they belong, but not to the area to which they moved, and this is what makes the old kept preserving the dialect that is associated with the tribe but not the dialect of the area if it is found to be different. As they are from the same origin and known to change the area where they live in the past, as a result of their attempts to find a suitable place for pastoral, Bedouins kept taking with them the dialect they use where ever they move, and this what might interpret the spread of the same dialect among them regardless of the place where they live. Needless to say that Bedouin tribes also have some kind of social and historical prestige. So, preserving Bedouin dialects to associate oneself with the prestigious powerful group is expected. On a historical level, the Bedouin dialect is indeed a dialect of a people whose history is deeply rooted in the history of the ancient Arab tribes that played important role in the history of Arabs in general. On the social level, many political and successful military leaders in the area belong to the Bedouin groups. Bedouin tribes are important social institutions. Changing the place does not mean changing the tribe, and thus, does not mean changing the dialect of the tribe. Social pressure exerted on the old to preserve the native dialect results in preserving the tribe original dialect to confirm that they belong to the same group.

\section{Conclusion}

The study shows that Bedouins who live in different areas might use the same dialect. Bedouins who live in Jordan and those who live in Saudi Arabia use the /ts/ variant of the $(\mathrm{K})$ variable and the /dz/ variant of the (Q) variable. Bedouins belong to tribes and this explains why the variants used by Bedouins are the same regardless of the place where they live. Belonging to the Bedouin group is reflected in the use of some variants which are known to be peculiar to the Bedouin people but not to the rural people.

Unlike Bedouins, rural people use the dialect of the place where they live. In different villages it is not unexpected to find different dialects. Furthermore, it was found that some rural people who belong to the same clan but live in different areas, use the variants of the areas where they live. Different variants of the same variable appear in their speech. Bedouins were consistent in using the same variants, namely the /ts/ and the [ds], even if they live in different places. For example Male Bedouin informants in Jordan and Saudi Arabia appear to use the variant /ts/ and almost in similar rate. $30 \%$ and $40 \%$, respectively. The local tradition of each tribe often shows that all its members, or all the members of one section, are descended from one man (Gubser, 1973). This enhances and strengthens the feeling of belonging to one's tribe. This in turn, is mirrored in preserving the tribes' habits and values. Part of this is also preserving the tribe's dialect. In addition, Bedouin tribes are considered important and powerful social institutions. Having in mind that the value attached to the social group is also attached to the linguistic form used by them (Walfram, 1997).

\section{References}

Abdel-Jawad, H. (1981). Lexical and Phonological Variation in Spoken Arabic in Amman. University of Pennsylvania dissertation.

Abdo, D. (1969). On stress and Arabic Phonology: a generative approach. Beirut: Khayats.

Al Khatib, M (1988). Sociolinguistic change in an expanding urban context. A case study of Irbid city, Jordan. PhD thesis. University of Durham.

Al-Wer, E. (1991). Phonological variation in the speech of women from three urban areas in Jordan. University of Essex. PhD dissertation.

Daher, J (1998). Gender In Linguistic Variation: The Variable (Q) In Damascus Arabic. In E, Benmamoun, M, Eid and N. Haeri (ed), Perspectives On Arabic Linguistics XI, 183-205. Amsterdam: Benjamins Publishing Company.

Eckert, P. (1997). Age as a Sociolinguistic Variable. In F.Coulmas (ed). The Handbook Of Sociolinguistics, 151-168. Oxford: Blackwell

El Salman, M. (2003). The [q] variant in the Arabic Dialect of Tirat Haifa. In D.Park(ed.). Anthropological Linguistics, $45,413-425$.

El Salman, M., and Al Haisoni, E. (2013). Arabic dialect used in the Northern West of Saudi Arabia Shamari Arabic. In Moha Ennaji (ed). Languages and Linguistics, 31, 47-57

Irshied, O. (1984). The phonology of Arabic: Bani Hassan - A Bedouin Jordanian Dialect. PhD thesis. University of Illinois at Urbana-Champain.

Kanakri, M. (1988). Style and style shifting in the speech of educated speakers of Jordanian Arabic. PhD Diss. University of Wisconsin-Madison.

Labov, W. (1966). The social stratification of English in NewYork City. Washington, DC: Center for Applied Linguistics.

Mesthrie, R. (2000). Clearing the ground: basic issues, concepts and approaches. In R. Mesthrie, J. Swann, A. Deumert and W. Leap (eds.), Introducing Sociolinguistics, 1-43. Edinburgh: Edinburgh University Press.

Milroy, J., and Milroy, L. (1978). Belfast: Change and variation in an urban vernacular. In Trudgill (1978) 19-36). University Press.

Trudgill, P. (1974). The Social Differentiation of English in Norwich. Cambridge: Cambridge University Press. Walters, K. (1991). Women, Men, and Linguistic variation in the Arab world. In B.Comrie and M. Eid (eds),Perspectives on Arabic LinguisticsIII, 197-229. Amsterdam: John Benjamins Publishing Company. 